\title{
A Piezoelectrically Actuated Ceramic-Si-Glass Microvalve FOR DISTRIBUTED COOLING SYSTEMS
}

\author{
Jong M. Park ${ }^{1}$, Ryan P. Taylor ${ }^{2}$, Allan T. Evans ${ }^{1}$, Tyler R. Brosten ${ }^{2}$, Gregory F. Nellis ${ }^{2}$, Sanford A. Klein ${ }^{2}$, \\ Jeffrey R. Feller ${ }^{3}$, Louis Salerno ${ }^{3}$, and Yogesh B. Gianchandani ${ }^{1}$ \\ ${ }^{1}$ Department of Electrical Engineering and Computer Science, University of Michigan, Ann Arbor \\ ${ }^{2}$ Department of Mechanical Engineering, University of Wisconsin, Madison \\ ${ }^{3}$ NASA Ames Research Center, Moffett Field, CA 94035
}

\begin{abstract}
This paper describes a normally-open, self-encapsulated, valve for modulating refrigerant flow in a cryogenic cooling system. The valve consists of a micromachined die fabricated from a silicon-on-insulator wafer and a glass wafer, a commercially available piezoelectric stack actuator, and Macor ceramic encapsulation that has overall dimensions of $1 \times 1 \times 1 \mathrm{~cm}^{3}$. A perimeter augmentation scheme for the valve seat has been implemented to provide high flow modulation. In tests performed at room temperature the flow was modulated from $980 \mathrm{~mL} / \mathrm{min}$. with the valve fully open $(0 \mathrm{~V})$, to $0 \mathrm{~mL} / \mathrm{min}$. with $60 \mathrm{~V}$ actuation voltage, at an inlet pressure of $55 \mathrm{kPa}$. Preliminary test results obtained at $80 \mathrm{~K}$ demonstrate that higher actuation voltages $(\approx 120$ $\mathrm{V})$ are required to close the valve. However, it shows consistent modulation capability regardless of inlet pressure up to approximately $1 \mathrm{~atm}$.
\end{abstract}

\section{INTRODUCTION}

Future space missions will require cooling of large systems such as optical assemblies or propellant depot stations with a high degree of temperature stability and small gradients. One solution is to create a distributed cooling network that uses actively controlled, micro-scale valves that are integrated with heat exchangers and sensors. More specifically, multiple cooling elements, each of which consists of actively controlled valves integrated with heat exchangers and temperature sensors, are positioned across the structure to be cooled. With each cooling element working independently in response to local sensors, temperature can be controlled efficiently. Figure 1 illustrates how each cooling element can be realized: (a) a flow of cryogenic fluid at the load temperature through exchangers positioned across the structure to be cooled, or (b) a flow of cryogenic fluid at a higher temperature and pressure through recuperative heat exchanger, taking advantage of Joule-Thompson refrigeration. Either way, having valves that work reliably at cryogenic temperatures with large flow modulation capability is essential. This paper reports the development and preliminary test results of piezoelectric valves fabricated from $\mathrm{Si}$, glass, and ceramic.

\section{DEVICE CONCEPTS AND OPERATION}

The general approach utilized for this valve is to push a bulk Si micromachined plate against a glass substrate that has the inlet and outlet holes in it. Out-of-plane actuation was chosen to reduce the likelihood of friction between the actuated part and the substrate. The valve requires high forces to displace the Si against inlet pressure that can exceed $1 \mathrm{~atm}$. for some cases. Piezoelectric actuation is attractive because it can provide high forces and consumes negligible DC power. Macor ${ }^{\circledR}$ (machinable glass ceramic) is chosen for encapsulation material because of low thermal expansion at low temperature. In addition, it is

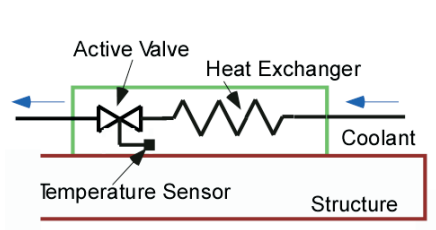

(a)
Recuperative Heat Exchanger

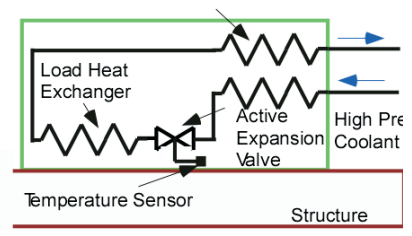

(b)
Fig. 1: Proposed application of actively controlled valve. Microvalves can (a) modulate flow of coolant in distributed heat exchangers, or (b) be used as expansion valves in Joule-Thompson cryocoolers.

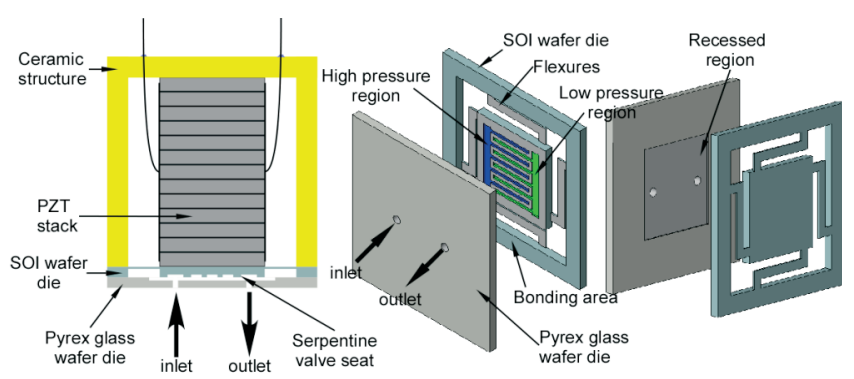

Fig. 2: Microvalve concepts: valve cross-section, ceramic-PZT-Si-glass structure is shown on the far left. Micro groove patterns to increase flow area are shown in the middle. The recessed glass along with the top view of Si piece is shown on the right.

machinable, capable of holding tight tolerances, and exhibits no outgassing and zero porosity.

Out-of-plane, stacked PZT actuation has been used widely in valves [1-4]. However, as each valve is constructed for different application, the performance goals are different. In our case, a normally open valve is desirable because the open condition is a safe failure mode, so that flow of the refrigerant is not blocked. For the same reason, an extremely tight seal is not essential. Instead, we need valves working at cryogenic temperatures, able to withstand several atm. of inlet pressure, and able to provide large flow modulation $(0-1000 \mathrm{~mL} / \mathrm{min})$.

The main challenge comes from the small displacement of PZT actuation, leading to modest flow modulation. Furthermore, the piezoelectric coefficient of PZT is substantially degraded at cryogenic temperatures [5], further reducing the displacement. We overcame this limited displacement by using perimeter augmentation. The flow area for an out-of-plane valve $\left(A_{\text {valve }}\right)$ is given by the product of the valve stroke $(\delta)$ and the perimeter of the valve seat $(p)$.

$$
A_{\text {valve }}=\delta \cdot p
$$

Thus, by increasing the perimeter of the valve seat, flow area can be increased substantially, which results in large flow modulation. Serpentine grooves are fabricated on the valve plate $\left(5 \times 5 \mathrm{~mm}^{2}\right)$ as shown schematically in Fig. 2, so that the perimeter measures about $127 \mathrm{~mm}$. Each groove measures $50 \mu \mathrm{m}$ wide and $120 \mu \mathrm{m}$ deep. The valve plate is suspended by four flexures of $500 \mu \mathrm{m}$ 
beam width. The valve has total foot print of $1 \times 1 \mathrm{~cm}^{2}$. (A picture of the grooves from fabricated device is shown in Fig. 6.)

\section{DEVICE FABRICATION}

To ensure control of material properties, the final device is comprised of only bulk materials; deposited thin films are not used for any structural layer, although they are used in intermediate steps. The fabrication process uses two wafers: a silicon-oninsulator (SOI) wafer which has device layer, buried oxide layer, and carrier wafer thicknesses of $50 \mu \mathrm{m}, 0.5 \mu \mathrm{m}$, and $450 \mu \mathrm{m}$, respectively, and a $500 \mu \mathrm{m}$ thick Pyrex glass wafer. The fabrication processes for SOI and glass wafers are illustrated in Fig. 3 and Fig. 4, respectively.

The use of the SOI wafer in the fabrication process permits the buried oxide layer to provide an etch stop for deep reactive ion etching (DRIE), while the epitaxial layer provides a wellcontrolled flexure thickness and bulk Si properties. The first DRIE process step etches down to the buried oxide layer from the top,

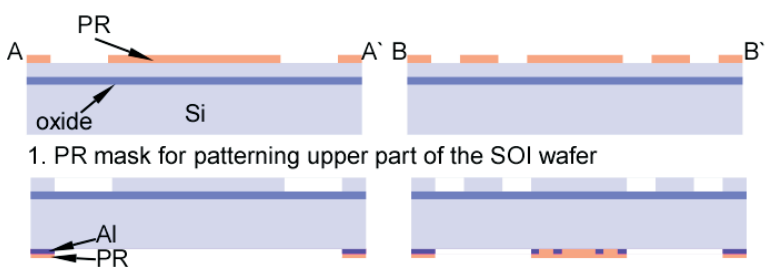

2. $\mathrm{PR}($ red) and $\mathrm{Al}$ (blue) mask for patterning lower part of the SOI wafer

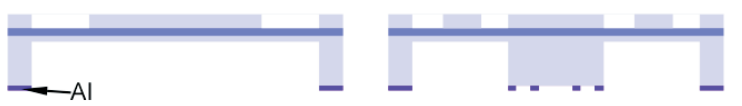

3. When almost finished remove PR and continue to etch grooves

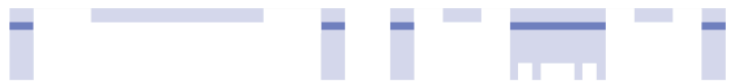

4. Remove oxide (insulating layer and mask) to achieve final structure.
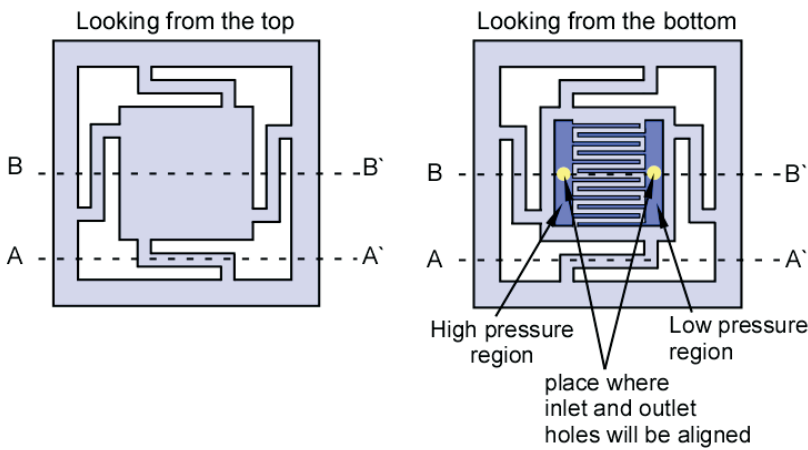

Fig. 3: SOI wafer micromachining process: the buried oxide layer acts as an etch stop for DRIE. A three step DRIE process is illustrated for the SOI wafer.

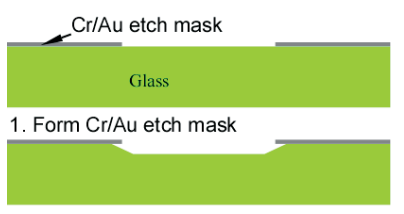

2. Wet etch glass in $\mathrm{HF}: \mathrm{HNO}_{3}$ solution

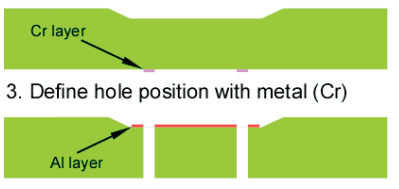

4. Create hole using electrochemical drilling process followed by Al deposition and defines the flexure structures. Then the bottom side is patterned with $\mathrm{Al}$ and photoresist. The photoresist pattern acts as etch mask for the second DRIE step that is approximately $400 \mu \mathrm{m}$ deep. Next, the photoresist is removed and $\mathrm{Al}$ is used as an etch mask for the final DRIE step, which engraves serpentine grooves for perimeter augmentation. The Al layer is then removed and the wafer is prepared for bonding.

A recess of $2 \mu \mathrm{m}$ is wet etched into the glass wafer in order to accommodate the PZT displacement (Fig. 4). A thin Cr layer (100 $\mathrm{nm}$ ) is patterned to define the position of inlet and outlet holes that are formed using electrochemical discharge machining (ECDM) [6]. ECDM of glass is a rapid, low cost method that provides a near-vertical profile and is suitable for hole formation. The procedure is performed in $40 \% \mathrm{NaOH}$ solution at room temperature, and the glass is machined using approximately 300 $\mu \mathrm{m}$ diameter tungsten cathode and $37 \mathrm{~V}$ bias. After the holes are formed, the residual $\mathrm{Cr}$ layer is removed.

A thin layer of $\mathrm{Al}$ must be deposited into the glass recess to prevent inadvertent bonding of the valve seat to the glass substrate due to shallow recess depth and very compliant flexures. Anodic bonding is performed at $400^{\circ} \mathrm{C}$ and $800 \mathrm{~V}$, after which the Al layer on SOI wafer is dissolved. The bonded wafers are then diced and prepared for assembly with the ceramic structure and PZT.

The final step is to attach the PZT stack and ceramic cap by

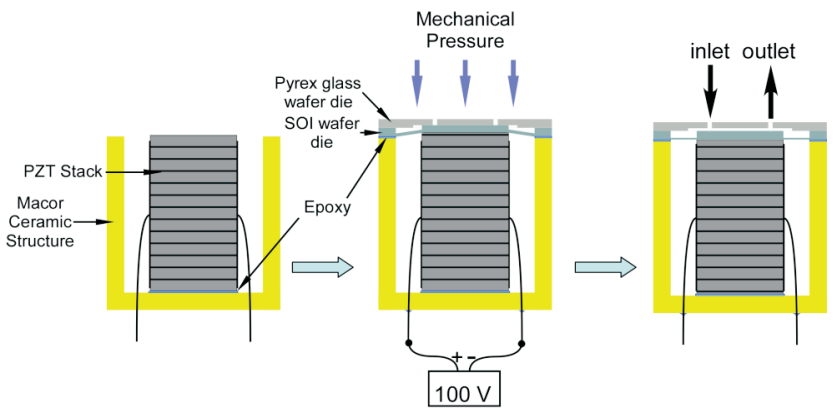

(a)

(b)

(c)

Fig. 5: Prestressed microvalve assembly procedure: (a) First, PZT stack is attached to the Macor ceramic structure using epoxy. (b) Then diced Si-glass die is bonded at the end of PZT and Macor structure by epoxy joint. During this procedure, the PZT stack is actuated until the epoxy is fully cured which results in a normally open valve (c).
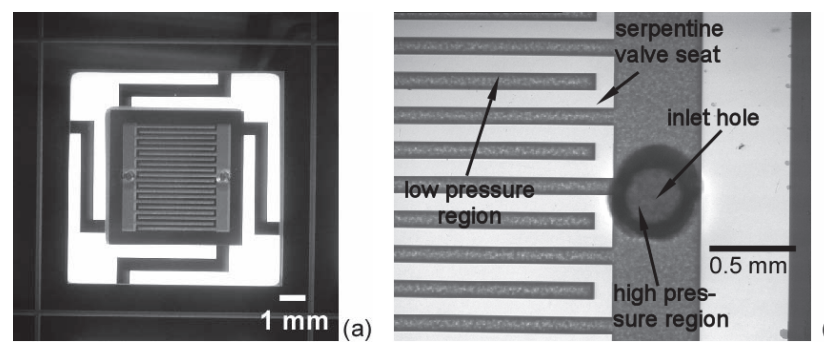

(b)

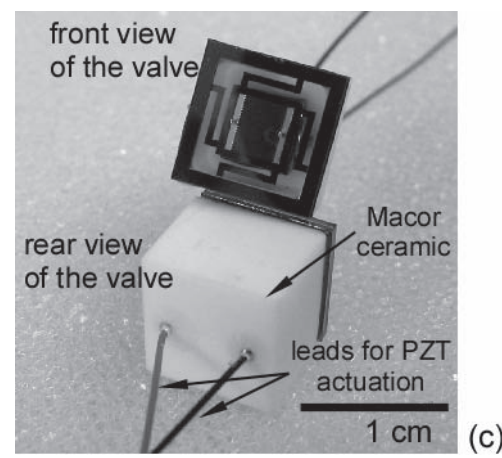

Fig. 6: Photographs of fabricated device. (a) Picture of a die after anodic bond. (b) Close-up view near the hole with serpentine groove pattern for perimeter augmentation. (c) Completed valve structure. Two valves (front and back) are shown. 
epoxy. The first prototype valve that was tested in room temperature was assembled using regular Devcon 2-part epoxy. However, Devcon epoxy is only rated down to $-40^{\circ} \mathrm{C}$, so for cryogenic testing, Stycast 2850 FT epoxy is used. To create a normally-open valve, the PZT stack is energized at $100 \mathrm{~V}$ during the assembly process, so that it shortens after assembly (Fig. 5). Note that the PZT need not be bonded to the $\mathrm{Si}$ - this would accommodate variations in its height caused by expansion mismatch between the PZT and the Macor, and also relieve any stress on flexures caused by large temperature variation. The completed valve structure is pictured in Fig. 6. The valve has dimensions of $1 \times 1 \times 1 \mathrm{~cm}^{3}$.

\section{EXPERIMENTAL AND MODELING RESULTS}

Preliminary tests were performed at room temperature with He gas flow. A schematic of the test is shown in Fig. 7. An in-line thermoplastic filter is placed upstream of the device to trap any particles or moisture. Pressure gauges are mounted so that inlet and outlet pressure can be monitored. Copper piping $(6.35 \mathrm{~mm} \varnothing)$ is connected to $0.4 \mathrm{~mm}$ holes in glass through an aluminum header. A ball valve is added at the end so that the outlet pressure can be controlled, if necessary.

In the first set of tests, the inlet pressure was regulated (21-55 $\mathrm{kPa}$ ), and the outlet was maintained at atmosphere, while the flow rate was measured over $0-60 \mathrm{~V}$ actuation. As shown in Fig. 8, as actuation voltage increases, the PZT expands, the clearance between silicon valve seat and glass substrate decreases, thus flow rate decreases. With $55 \mathrm{kPa}$ of inlet pressure, flow rate could be modulated from 0 to $980 \mathrm{~mL} / \mathrm{min}$. At $60 \mathrm{~V}$, the valve leakage was below the measurement limit $(<0.1 \mathrm{~mL} / \mathrm{min}$.).

These test results were compared with prediction from numerical flow model (Fig. 9). The model used a combination of reduced Navier Stokes 2-d equations and empirical formulations. The flow through the grooves was simplified by assuming that the fluid is incompressible, laminar, constant viscosity, and hydrodynamically fully developed. In this limit, the pressure gradient in the groove is related to the local mass flow rate $(\dot{m})$ according to:

$$
\frac{d p}{d x}=-\frac{K \mu p e r_{g}^{2}}{32 \rho A_{c, g}^{3}} \dot{m}
$$

where $p$ is the local pressure, $\mu$ and $\rho$ are the viscosity and density of the fluid, respectively, both of which are assumed to be constant, per $_{g}$ and $A_{c, g}$ are the perimeter and cross-sectional area of the groove. The parameter $K$ is a constant that depends on the groove aspect ratio. Flow through the land region was assumed to be governed by a reduced form of the 2-d Navier Stokes equations shown in Eqn. (3).

$$
\frac{\partial u_{m}}{\partial x}+\frac{\partial v_{m}}{\partial y}=0
$$

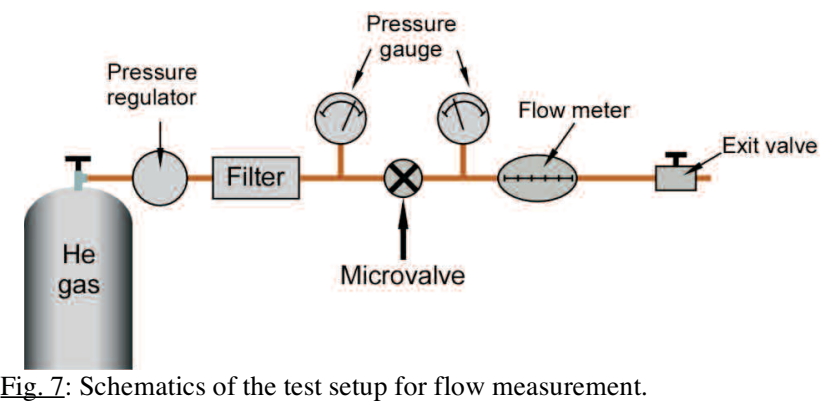

where $u_{m}$ and $v_{m}$ are the average local $x$ and $y$ velocities through the land, related to the pressure gradient by:

$$
\begin{aligned}
& u_{m}=-\frac{h^{2}}{12 \mu} \frac{\partial p}{\partial x} \\
& v_{m}=-\frac{h^{2}}{12 \mu} \frac{\partial p}{\partial y}
\end{aligned}
$$

where $h$ is the valve seat clearance. The above set of equations were discretized in a single land and groove then solved using sparse matrix decomposition in the Matlab $\mathbb{C}$ environment. The results of the model were characterized using a set of nondimensional numbers governing the flow through a single land and groove. Using the derived non-dimensional relations, a second full valve model was developed and implemented using Engineering Equation Solver (EES) in order to determine the simulated flow rate.

The Fig. 9 was obtained by assuming that the hole diameters for inlet and outlet are $350 \mu \mathrm{m}$ and displacement of PZT at $60 \mathrm{~V}$ is $4 \mu \mathrm{m}$. In addition, a linear relationship between PZT displacement and voltage was assumed. Thus, seat clearance from the glass substrate can be expressed as in Eqn. (6).

$$
\text { Clearance }(\mu \mathrm{m})=4-\operatorname{Voltage}(\mathrm{V}) \cdot 0.067
$$

The flow rates from the model tend to fall slightly faster than the experimental results, but in general they match reasonably well. The main discrepancy comes from uncertainties in seat clearance and inaccurate inlet and outlet hole size used in the model. Compressibility of He gas and hysteretic behavior of PZT also contribute to the difference between the model and experimental data.

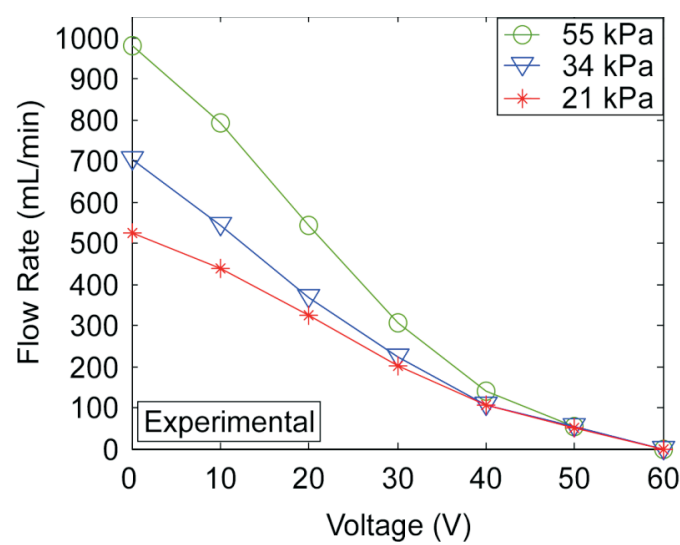

Fig. 8: Flow rates as a function of voltage are plotted. As the actuation voltage increases, the valve is closed which results in a decrease in flow rate.

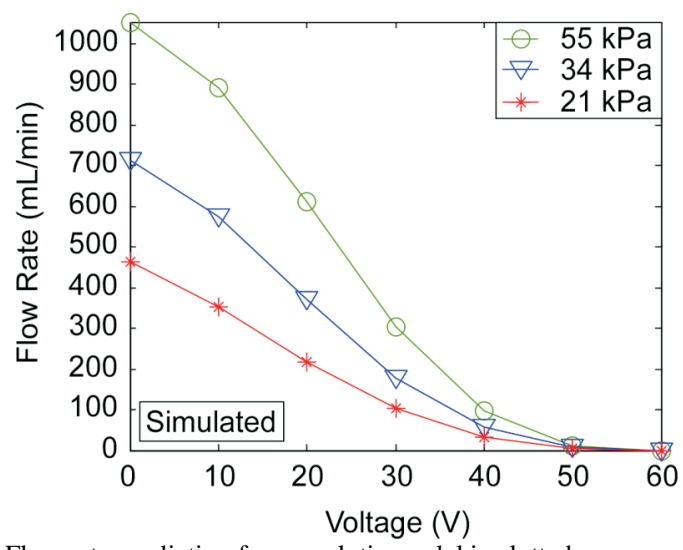

Fig. 9: Flow rate prediction from analytic model is plotted. 


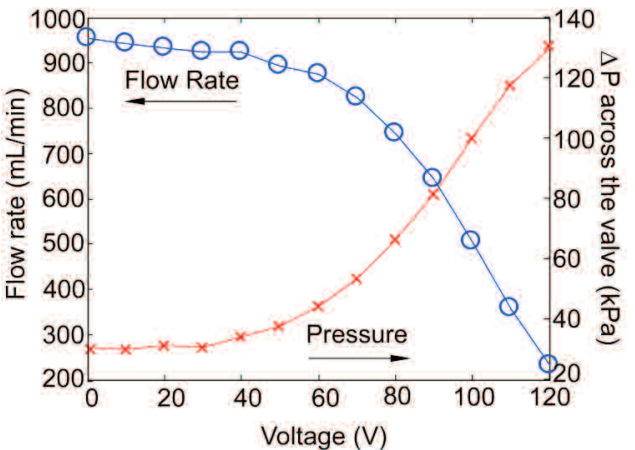

Fig. 10: Flow rate and inlet to outlet pressure differential as the valve with an inlet pressure of $145 \mathrm{kPa}$ goes from being wide open $(0 \mathrm{~V})$ to completely closed $(120 \mathrm{~V})$

In a separate experiment, a pressure drop across the valve was recorded along with the flow rate as the actuation voltage was varied from 0 to $120 \mathrm{~V}$ (Fig. 10). At $145 \mathrm{kPa}$ inlet pressure, 28 $\mathrm{kPa}$ pressure drop across the valve was obtained by partially closing the exit valve, and flow rate of $950 \mathrm{~mL} / \mathrm{min}$. was recorded. As the actuation voltage was increased, the valve restricted more flow while sustaining larger pressure drop across the valve. At $120 \mathrm{~V}$, it sustained a pressure drop of $130 \mathrm{kPa}$.

In order to verify the operations of the valve at cryogenic temperatures, another set of experiment was performed near liquid nitrogen temperature $(80 \mathrm{~K})$. (For this valve Stycast epoxy was used, and the PZT was not bonded to the Si valve plate.) The test setup is schematically shown in Fig. 11. The He gas was cooled by passing it through liquid nitrogen heat exchanger. Inlet and outlet pressure were monitored. In addition, thermocouples were used to probe inlet and outlet gas temperature. The gas was then passed through another heat exchanger to bring it back to room temperature and exhausted to atmosphere, while the flow rate was measured. The valve performance is shown in Fig. 12 for inlet pressures $35 \mathrm{kPa}, 70 \mathrm{kPa}$, and $104 \mathrm{kPa}$. Compared to the room temperature results, higher voltages were needed to completely close the valve. This is likely the result of degraded piezoelectric coefficient at cryogenic temperatures [5]. The normalized flow rate (NFR) is presented in Fig. 13. This is defined as:

$$
N F R=\frac{\text { flow rate at corresponding voltage }}{\text { flow rate at } 0 \mathrm{~V}}
$$

In Fig. 13, the three curves obtained at different inlet pressures look very similar to each other. This illustrates consistent modulation of the valve over the range of inlet pressures tested.

\section{CONCLUSIONS}

This effort has resulted in the successful fabrication of a piezoelectrically actuated ceramic-Si-glass microvalve for distributed cooling application. A perimeter augmentation scheme was used to overcome limited displacement of PZT and provide large flow modulation. At room temperature, flow rate of 980 $\mathrm{mL} / \mathrm{min}$. was measure with inlet pressure of $55 \mathrm{kPa}$. At cryogenic

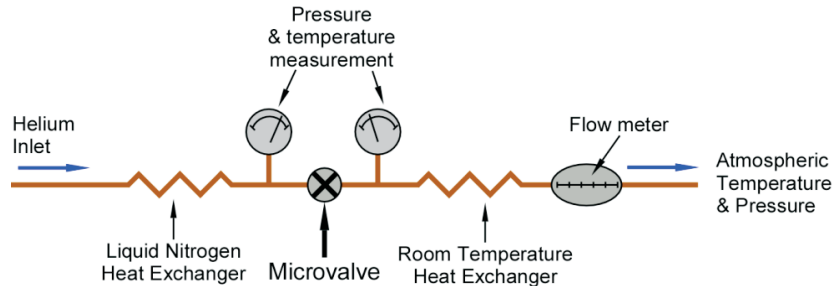

Fig. 11: Schematics of the test setup for cryogenic flow measurement.

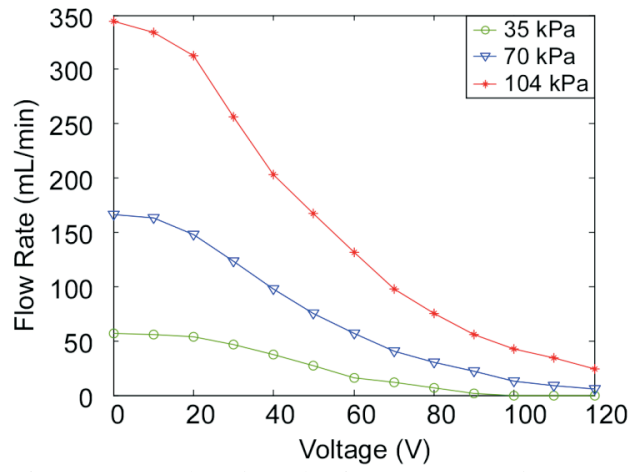

Fig. 12: Flow rates as a function of voltage at cryogenic temperature.

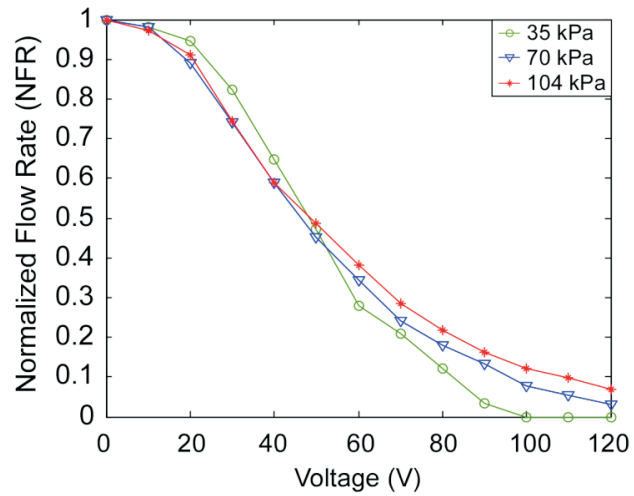

Fig. 13: Normalized flow rate vs. actuation voltage obtained at cryogenic temperature.

temperatures, it required higher voltage to completely close the valve due to degraded piezoelectric coefficient, but it showed consistent modulation capability.

\section{ACKNOWLEDGEMENTS}

The authors are grateful to the Michigan Nanofabrication Facility at the University of Michigan. The authors also appreciate Daniel Hoch at University of Wisconsin for valuable discussion. This work is supported primarily by NASA under award NNA05CP85G.

\section{REFERENCES}

[1] I. Chakraborty, W.C. Tang, D.P. Bame, T.K. Tang, "MEMS Micro-valve for Space Applications," Sensors and Actuators, V. 83, pp. 188-193, 2000

[2] M. Esashi, S. Shoji, A. Nakano, "Normally Closed Microvalve and Micropump Fabricated on a Silicon Wafer," Sensors and Actutors, V. 20, pp. 163-169, 1989

[3] S. Shoji, B. Schoot, N. Rooij, M. Esashi, "Smallest Dead Volume Microvalves for Integrated Chemical Analyzing Systems," Transducers '91, pp. 1052-1055, 1991

[4] C. Lee, E.H. Yang, "A Piezoelectric Liquid-Compatible Microvalve for Integrated Micropropulsion," Technical Digest of the 2004 Solid-State Sensor and Actuator Workshop, Hilton Head Isl., SC, 6/6-10/04, pp. 160-163, 2004

[5] R.P. Taylor, G.F. Nellis, S.A. Klein, D.W. Hoch, J. Fellers, P. Roach, J.M. Park, Y. Gianchandani, "Measurements of the Material Properties of a Laminated Piezoelectric Stack at Cryogenic Temperatures," International Cryogenic Materials Conference, 2005, in press.

[6] V. Fascio, R. Wuthrich, D. Viquerat, H. Langen, "3D Microstructuring of Glass Using Electrochemical Discharge Machining (ECDM)," International Symposium on Micromechatronics and Human Science, pp. 179-183, 1999 